2002s-16

\title{
Asymmetric Information and Product Differentiation
}

\author{
Marcel Boyer, Philippe Mahenc, \\ Michel Moreaux
}

\begin{tabular}{c}
\hline Série Scientifique \\
Scientific Series
\end{tabular}

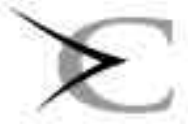

CI RA N N

en unilyse den organisifions:

Montréal

Février 2002 


\section{CIRANO}

Le CIRANO est un organisme sans but lucratif constitué en vertu de la Loi des compagnies du Québec. Le financement de son infrastructure et de ses activités de recherche provient des cotisations de ses organisationsmembres, d'une subvention d'infrastructure du ministère de la Recherche, de la Science et de la Technologie, de même que des subventions et mandats obtenus par ses équipes de recherche.

CIRANO is a private non-profit organization incorporated under the Québec Companies Act. Its infrastructure and research activities are funded through fees paid by member organizations, an infrastructure grant from the Ministère de la Recherche, de la Science et de la Technologie, and grants and research mandates obtained by its research teams.

\section{Les organisations-partenaires / The Partner Organizations}

-École des Hautes Études Commerciales

-École Polytechnique de Montréal

-Université Concordia

-Université de Montréal

-Université du Québec à Montréal

-Université Laval

-Université McGill

-Ministère des Finances du Québec

-MRST

-Alcan inc.

-AXA Canada

-Banque du Canada

-Banque Laurentienne du Canada

-Banque Nationale du Canada

-Banque Royale du Canada

-Bell Canada

-Bombardier

-Bourse de Montréal

-Développement des ressources humaines Canada (DRHC)

-Fédération des caisses Desjardins du Québec

-Hydro-Québec

-Industrie Canada

-Pratt \& Whitney Canada Inc.

-Raymond Chabot Grant Thornton

-Ville de Montréal

(C) 2002 Marcel Boyer, Philippe Mahenc et Michel Moreaux. Tous droits réservés. All rights reserved. Reproduction partielle permise avec citation du document source, incluant la notice ().

Short sections may be quoted without explicit permission, if full credit, including $\odot$ notice, is given to the source.

Les cahiers de la série scientifique $(\mathrm{CS})$ visent à rendre accessibles des résultats de recherche effectuée au CIRANO afin de susciter échanges et commentaires. Ces cahiers sont écrits dans le style des publications scientifiques. Les idées et les opinions émises sont sous l'unique responsabilité des auteurs et ne représentent pas nécessairement les positions du CIRANO ou de ses partenaires.

This paper presents research carried out at CIRANO and aims at encouraging discussion and comment. The observations and viewpoints expressed are the sole responsibility of the authors. They do not necessarily represent positions of CIRANO or its partners.

\section{ISSN 1198-8177}




\title{
Asymmetric Information And Product Differentiation*
}

\author{
Marcel Boyer ${ }^{\dagger}$, Philippe Mahenc ${ }^{*}$ and Michel Moreaux ${ }^{\S}$,
}

\section{Résumé /Abstract}

Nous montrons que l'asymétrie d'information peut ne causer aucune distorsion dans la différentiation des produits. Ce résultat va à l'encontre de ceux prévalant dans la littérature sur les signaux, littérature qui soutient que l'asymétrie d'information modifie de manière non négligeable les comportements stratégiques. Une analyse approfondie des contre-incitations pour la dissimulation d'information révèle des modifications sous-jacentes importantes menant aux mêmes observations d'équilibre en information complète et incomplète. L'absence de modifications apparentes dans les localisations d'équilibre repose sur des changements invisibles dans les stratégies, le suiveur modifiant de façon cruciale sa meilleure réponse à la localisation de la firme établie.

We show that information asymmetry may not cause any distortion in product differentiation. This contrasts with the main result of the literature on signaling which stresses that information asymmetry has a non negligible impact on strategic behavior. A thorough analysis of the counter-incentives for information concealment shows that much is going on beneath the surface to yield the same equilibrium behaviors under complete and incomplete information. The absence of visible changes in equilibrium locations relies on invisible changes in strategies. There is a crucial modification in the follower's best response to the incumbent's location due to incomplete information.

Mots-clés : Information asymétrique, Localisation, Différentiation de produit

Keywords: Asymmetric information, Location, Product Differentiation

JEL: D43, D82, L13.

\footnotetext{
*Corresponding author: Marcel Boyer, CIRANO, Université de Montréal, 2020 University, $25^{\text {ème }}$ étage, Montréal, H3A 2A5, Canada. Tel: +1 (514) 985-4002, FAX: +1 (514) 985-4035, email: marcel.boyer@ cirano.qc.ca.

${ }^{\dagger}$ Université de Montréal and CIRANO.

* Université de Perpignan and GREMAQ, Université de Toulouse.

${ }^{\S}$ Université de Toulouse I, IDEI and LEERNA-INRA.
} 


\section{Introduction}

In a spatial competition context under incomplete information, mimicry needs space to be effective. However, the extent of product differentiation is naturally confined by the market boundaries interpreted either literally as geographic limits or as extreme varieties delimiting the scope of consumers' tastes. We examine this idea in the present article by analyzing the robustness of the d'Aspremont et al. (1979) "maximum differentiation principle" to the introduction of asymmetric information. Following d'Aspremont et al. (1979), we assume mill price competition and quadratic transportation costs. The assumption of quadratic transportation costs can be defended on two grounds. First, in preference space, it is the natural assumption to make: the loss in utility (from tuning, redesigning, adapting) experienced by a consumer, when the characteristics of the product he buys differ from his own most preferred product characteristics, is increasingly large the further away the product location is. ${ }^{1}$ Second, the assumption is a simple way to obtain the existence of a pure-strategy equilibrium in price, a major theoretical problem in the Hotelling linear framework.

In a first analysis of competition over product characteristics (spatial) under incomplete information published in a recent issue of this journal, Boyer et al. (1994) showed that product differentiation will indeed be distorted by incomplete information. In their duopoly sequential location model with discriminatory pricing and linear transportation costs, firm 1 is either a low or high cost firm while firm 2 is a high cost firm. Firm 1 is an incumbent first mover firm which chooses its location or product characteristics knowing its type while firm 2 is a second mover firm ignoring the type of firm 1 , but choosing its location after observing the location of firm 1. Under complete information, the presence of a low cost incumbent may generate more or less differentiation than the presence of a high cost one. Under incomplete information, a low cost incumbent distorts her full information location in order to credibly convey information on her true cost. This distorted choice may deter mimicking by a high cost incumbent because it reduces the degree of product differentiation and thereby increases price competition. However, a high cost firm 1 may gain in mimicking the location of its low cost counterpart by moving aggressively towards the center of the market. Depending on the prior probabilities of the two types of firm 1, the bluff induces a move by firm 2 away from the center but nevertheless product differentiation is reduced. Hence information asymmetry matters in this product design competition context. ${ }^{2}$ 
However, when "transportation" costs are assumed quadratic and borne by the consumers, the story is quite different. We develop in this paper such a model where, for a wide range of parameter values, asymmetric information does not give rise to distortions in product differentiation. Hence those results complement the results of Boyer et al. (1994, 1995) and allow a better understanding of the role of asymmetric information in shaping strategic behavior. We first reconsider the complete information analysis of d'Aspremont et al. (1979) by including a positive cost differential between the duopolists. We show that differentiation remains important but in general not maximal, that is firms need not locate at the end points of the market. Restricting our analysis to cost differentials for which both firms capture a positive market share in equilibrium, we show that in an attempt to avoid harsh price competition in stage 2 , the second mover firm locates in equilibrium at the fringe of the market even if it benefits from a cost advantage. We show that the extreme equilibrium of "maximum differentiation" is not distorted by the incomplete information precisely because it is so extreme.

The intuition is the following: unlike what usually emerges in standard models of signaling, the weak type, that is the high cost incumbent here, has no incentive to mimic the strong type by moving towards the market center because such a strategic move would reduce differentiation, hence increase price competition thereafter. As a result, signaling one's true type via location may not require any distortion and incomplete information does not seem on the surface to play an important role in spatial competition with quadratic transportation costs.

However, a thorough analysis of the counter-incentives for information concealment shows that much is going on beneath the surface to yield the same equilibrium behaviors under complete and incomplete information. The absence of visible changes in equilibrium locations relies on invisible changes in the duopolists' strategies. In particular, there is a crucial modification in the follower's best response to the incumbent's location due to incomplete information. When the uninformed follower observes an incumbent's location near the opposite fringe of the market, he differentiates his product to the maximum in equilibrium no matter what he believes about the other's type: this is the same "puppy dog" strategy as the classical one leading to maximal differentiation under complete information. By contrast, when the uninformed follower observes an incumbent's location closer to the market center, he may spurn his extreme location to move towards the market center, and may even reach the market center, if he is convinced to compete against the high cost type, while he sticks to the market boundary if he thinks the incumbent to be the low cost type. Anticipating the follower's reaction, the high cost incumbent cannot 
profitably choose the same aggressive location, somewhat closer to the market center, as her low cost counterpart. Indeed, even if by doing so he was thought to be the low cost type, her competitor could not differentiate beyond the market boundary. But the high cost incumbent achieves the same result - the follower's reaction at the opposite market boundary - with less aggressive location involving more differentiation. In other words, by mimicking and bluffing, the high cost incumbent would reduce product differentiation without inducing the competitor to move further away. Thus the high cost incumbent is better off choosing her full information equilibrium location: product differentiation is then maximal. Moreover the low cost incumbent does not need to choose a distorted location and incur a signaling cost since mimicry is unprofitable. Hence the low cost incumbent chooses also her full information equilibrium location: product differentiation is maximal for small cost differentials and somewhat less than maximal for large ones.

In section 2, we reconsider the analysis of d'Aspremont et al. (1979) under complete information and derive the perfect Nash equilibrium in locations for a wide range of parameter values. In section 3, we present the model under asymmetric information and characterize the duopolist's equilibrium choices in location. We discuss the robustness of our results to changes in the assumptions on asymmetric information in section 4 . We offer concluding remarks in section 5 .

\section{Basic Model Under Complete Information}

We shall first recall the modified version of Hotelling's (1929) duopoly model proposed by d'Aspremont et al. (1979). The only change we introduce in this section is that the two firms are assumed to bear different unit production cost. Although slight, the modification gives rise to new considerations since a lower [higher] cost competitor benefits from more [less] market power than a same cost competitor.

Consumers are uniformly distributed along an interval $[0, \ell]$ and each consumer buys one unit of some homogeneous product. The full price is the uniform mill price plus the transportation cost incurred by the consumer. Firm 1 [2] locates within the left [right] half of the market area at distance $x_{1}\left[x_{2}\right]$ from 0 . Firm $i, i=1,2$, bears a constant marginal cost of production $C_{i}$. Let $\Delta$ denote the cost differential $C_{1}-C_{2}$ and let $p_{1}$ and $p_{2}$ denote, respectively, the mill prices of firm 1 and firm 2. The transportation cost is given by $k d^{2}$, where $k$ is a constant and $d$ is the 
distance between the consumer and the firm.

In this section the firms are assumed to act under complete information. The game we consider unfolds as follows: firm 1 plays first and commits to its location; firm 2 observes this decision and chooses its own location; both firms then set prices simultaneously. In the following section, firm 2 will be assumed to suffer from limited information and seek to infer firm 1's cost from observing its location. The firms' profits and demand curves are derived in Appendix A1. Conditions for a unique perfect price-location equilibrium to exist are met. As advocated by Hotelling (1929) and d'Aspremont et al. (1979), when firms choose their locations in stage 1 , they both anticipate the consequences of their choice on price competition in stage 2 . Non credible threats are of no avail. The concept of perfect equilibrium captures this idea.

The concave demand and profit functions ensure the existence of the Nash equilibrium in prices, the expression of which is given in the following lemma.

Lemma 1: The unique subgame perfect price equilibrium is given by

$$
\begin{gathered}
p_{1}^{N}\left(x_{1}, x_{2}\right)=\frac{1}{3}\left(2 C_{1}+C_{2}+k\left(x_{2}-x_{1}\right)\left(2 \ell+x_{1}+x_{2}\right)\right) \\
p_{2}^{N}\left(x_{1}, x_{2}\right)=\frac{1}{3}\left(C_{1}+2 C_{2}+k\left(x_{2}-x_{1}\right)\left(4 \ell-x_{1}-x_{2}\right)\right) . \|
\end{gathered}
$$

We obtain from these expressions, the firms' reduced-form profit functions conditional on their locations. We first consider that firm 1 bears higher cost, $\Delta>0$, before considering the case where $\Delta<0$.

If firm 1 suffers from a cost disadvantage, price competition may drive prices down to a level at which there is no demand for firm 1's product. The incentive of firm 2 to differentiate, that is to choose a location away from that of firm 1, may conflict with the benefit it can obtain by monopolizing the whole market. We show in Appendix A2 that, for values of $\Delta$ sufficiently high $\left(\Delta / k>5 \ell^{2} / 4\right)$, given firm 1's location, there exists an interval of locations in the neighborhood of the market center, namely $\left[\ell / 2,-\ell+\left(\left(x_{1}+\ell\right)^{2}+\Delta / k\right)^{1 / 2}\right]$, which allows firm 2 to capture the whole market. Firm 1 is aware that price competition will be relaxed if it moves away from the center, that is towards the left edge of the market. However the most stringent effort to differentiate, that is locating at the left boundary of the market, may not be sufficient to get a positive market share because the price competition may still be too severe for firm 1 . This 
would occur if firm 2 had a large cost advantage or if the products could not be sufficiently differentiated, either because the market is of insufficient length (size) or because the factor $k$ is small, that is the marginal transportation cost is increasing too slowly with distance. For values of $\Delta / k$ low enough, there exists a location interval in the neighborhood of the left edge, namely in $\left[0,-\ell+\left(9 \ell^{2} / 4-\Delta / k\right)^{1 / 2}\right)$, that allows firm 1 to enjoy a positive market share and profit whatever firm 2's location. These results are summarized in Lemma 2 [with proof in Appendix A2]. Let $D_{i}\left(x_{1}, x_{2}\right)$ denote firm $i$ 's reduced-form demand function obtained by substituting the expressions of the prices given in Lemma 1 into the demand function $D_{i}\left(x_{1}, x_{2}, p_{1}, p_{2}\right)$ derived in Appendix A1.

Lemma 2: If $0<\Delta / k \leq 5 \ell^{2} / 4$ then, for any $x_{1} \in\left[0,-\ell+\left(9 \ell^{2} / 4-\Delta / k\right)^{1 / 2}[\right.$ and any $x_{2} \in[\ell / 2, \ell]$, we have $D_{1}\left(x_{1}, x_{2}\right)>0$. If $5 \ell^{2} / 4 \leq \Delta / k$ then, for any $x_{1} \in[0, \ell / 2]$ and any $x_{2} \in\left[\ell / 2,-\ell+\left(\left(x_{1}+\ell\right)^{2}+\Delta / k\right)^{1 / 2}\right]$, we have $D_{1}\left(x_{1}, x_{2}\right)=0$. $\|$

We restrict our attention to values of $\Delta / k$ lower than $5 \ell^{2} / 4$ to ensure that both firms are present on the market in stage 2; from lemma 2, there exists a non-empty interval of locations in the neighborhood of the left end point, that allows firm 1 to get a positive market share and profit. Thus there is no possibility of entry foreclosure by firm 2 for $\Delta / k \in\left(0,5 \ell^{2} / 4\right)$

As established by the following proposition, maximal differentiation emerges in equilibrium for values $\Delta / k \in\left[0, \ell^{2}\right)$. Despite its higher production cost, firm 1 obtains a positive market share. Given that firm 1 locates at the left edge of the market, firm 2's optimal reaction is to move as far away as possible. However firm 2's best strategy may not be maximal differentiation for some out of equilibrium location $x_{1}$, even in a duopolistic situation. Let $x_{2}^{+}\left(x_{1}\right)$ denote the location to the left of $\ell$ that maximizes firm 2's profit. The expression of $x_{2}^{+}\left(x_{1}\right)$ is given in Appendix A3 together with the reduced-form profit function $\hat{\pi}\left(x_{1}\right)$ of firm 1. 
Proposition 1: If firm 1 is a high cost firm $(\Delta / k>0)$, the perfect Nash equilibrium location strategies are given by:

1. If $0 \leq \Delta / k \leq 3 \ell^{2} / 4$,

$$
x_{1}^{N}=0 \text { and } x_{2}^{N}\left(x_{1}\right)=\left\{\begin{array}{l}
\ell, \text { for } x_{1} \in\left[0,\left(9 \ell^{2} / 4-\Delta / k\right)^{1 / 2}-\ell\right) \\
\left.\ell / 2, \text { for } x_{1} \in\left[\left(9 \ell^{2} / 4-\Delta / k\right)^{1 / 2}-\ell\right), \ell / 2\right] .
\end{array}\right.
$$

2. If $3 \ell^{2} / 4<\Delta / k<\ell^{2}$,

$$
x_{1}^{N}=0 \text { and } x_{2}^{N}\left(x_{1}\right)=\left\{\begin{array}{l}
\ell, \text { for } x_{1} \in\left[0,\left(\ell^{2}-\Delta / k\right)^{1 / 2}\right] \\
x_{2}^{+}\left(x_{1}\right), \text { for } x_{1} \in\left[\left(\ell^{2}-\Delta / k\right)^{1 / 2},\left(9 \ell^{2} / 4-\Delta / k\right)^{1 / 2}-\ell\right) \\
\ell / 2, \text { otherwise. }
\end{array}\right.
$$

3. If $\ell^{2}<\Delta / k<5 \ell^{2} / 4$,

$$
x_{1}^{N}=0 \text { and } x_{2}^{N}\left(x_{1}\right)=\left\{\begin{array}{l}
x_{2}^{+}\left(x_{1}\right), \text { for } x_{1} \in\left[0,\left(9 \ell^{2} / 4-\Delta / k\right)^{1 / 2}-\ell\right) \\
\ell / 2, \text { otherwise. } \|
\end{array}\right.
$$

The second part of Proposition 1 states that firm 2 would choose to locate at $x_{2}^{+}\left(x_{1}\right)$, that is not decide to move as far as possible from its competitor, if firm 1's location is sufficiently far from both the left end point and the market center. However this reduction in product differentiation would entail a decrease in firm 1's profit. Anticipating this, firm 1 is better off locating at the left end point to induce maximal differentiation from firm 2 . Thus - and this is the main result of the analysis under complete information - if firm 1's location is observed to be sufficiently close to the left end point of the market, firm 2 sticks to the right edge despite its advantage in production cost.

A fortiori, firm 2 is expected to have such a puppy dog behavior when it incurs a higher cost than firm 1 , that is when $\Delta<0$. The analysis of this case is symmetric to the previous one: it is now firm 2's profit which may be reduced to zero depending upon firm 1's location. However, for values of $\Delta / k$ larger than $-5 \ell^{2} / 4$, firm 2 can obtain a positive market share and profit by locating in the neighborhood of the right end point. More precisely, we state the following lemma, the proof of which can be found in Appendix A4:

Lemma 3: If $-5 \ell^{2} / 4<\Delta / k \leq 0$, then, for any $x_{1} \in[0, \ell / 2]$ and any $x_{2} \in\left(2 \ell-\left(9 \ell^{2} / 4+\Delta / k\right)^{1 / 2}, \ell\right]$, we have $p_{2}^{N}\left(x_{1}, x_{2}\right)>C_{2}$ and $D_{2}\left(x_{1}, x_{2}\right)>0$. $\|$ 
A glance at the expression of $\partial \pi_{2} / \partial x_{2}$, given in Appendix A3, shows that, regardless of the location of firm 1 , the profit of firm 2 increases with $x_{2}$. Hence firm 1 expects firm 2's optimal reaction to be at the right end point of the market whatever its own location. It follows from the study of $\hat{\pi}_{1}\left(x_{1}\right)$, that is firm 1's profit given firm 2's optimal reaction, that firm 1's optimal location is not always at $0 .^{3}$

Proposition 2: If firm 1 is a low cost firm $(\Delta / k<0)$, the perfect Nash equilibrium location strategies are given by

1. If $-\ell^{2} \leq \Delta / k \leq 0$

$$
x_{1}^{N}=0 \text { and } x_{2}^{N}\left(x_{1}\right)=\ell \text { for any } x_{1} \in[0, \ell / 2] .
$$

2. If $-5 \ell^{2} / 4<\Delta / k \leq-\ell^{2}$,

$$
x_{1}^{N}=\left(\ell-\left(4 \ell^{2}+3 \Delta / k\right)^{1 / 2}\right) / 3 \text { and } x_{2}^{N}\left(x_{1}\right)=\ell \text { for any } x_{1} \in[0, \ell / 2] . \|
$$

Thus, if firm 1's production cost is sufficiently low relative to that of firm 2, maximal differentiation does not occur in equilibrium. The reason is given by the expression of firm 1's marginal demand:

$$
\frac{\partial D_{1}\left(x_{1}, x_{2}\right)}{\partial x_{1}}=\frac{3 \ell-5 x_{1}}{6\left(\ell-x_{1}\right)}-\frac{\Delta}{6 k\left(\ell-x_{1}\right)^{2}} .
$$

It can be seen that a huge cost differential has a direct impact on the increase in firm 1's market share when it moves toward the market center, hence the tendency that opposes maximal differentiation is strengthened.

\section{Asymmetric Information}

Whatever the cost difference, either a cost advantage resulting from past experience or a cost disadvantage resulting from the development of some form of X-inefficiency, it is reasonable to assume that it is a private information, at least in numerous cases. We will assume therefore that, at the beginning of the game, firm 1 learns its true production cost and that firm 2 ignores whether it has a cost advantage of not. Being uncertain about which firm has the cost advantage, firm 2 can act as a follower in location in order to infer some information about firm 1's cost from the observation of the latter's location choice. ${ }^{4}$ Understanding this, firm 1 can influence through its choice of location the inference firm 2 will make about the true cost advantage and 
thus the latter's location choice.

Information about $\operatorname{costs} C_{i}, i=1,2$, is therefore asymmetric: firm 2's cost is common knowledge while whether firm 1's cost is high $\overline{C_{1}}$ or low $\underline{C_{1}}$ is a private information of firm 1 . We will assume that firm 2 believes a priori that it has a cost disadvantage $\left(\underline{\Delta}=\underline{C_{1}}-C_{2}<0\right)$ with probability $\mu_{0}$, and a cost advantage $\left(\bar{\Delta}=\overline{C_{1}}-C_{2}>0\right)$ with probability $1-\mu_{0}$. The distribution of firm 2's prior beliefs is common knowledge. Firm 2 will update its beliefs about the cost differential after observing the location of firm 1 . Let $\mu\left(x_{1}\right)$ be firm 2's posterior belief that the cost differential is negative (firm 1 is more efficient) when firm 1's location is $x_{1}$. The objective of firm 2 is then to maximize its expected profit given its beliefs. In order to focus attention on the strategic interactions, we restrict the analysis to the following range of parameter values: $\underline{\Delta} / k$ belongs to $\left(-5 \ell^{2} / 4,0\right)$ and $\bar{\Delta} / k$ belongs to $\left(0, \ell^{2}\right)$.

Although firm 2 may not know the true cost of firm 1 at the location stage (unless it is perfectly inferred from firm 1's location choice), firm 2 is assumed to learn this cost before price competition takes place. Such an assumption is consistent with the view that location choices are long-run decisions made before all market conditions are known but that over time the cost parameters of all firms will become perfectly known because of the repeated interactions on markets. We do not model this process but rather assume that in the second stage the firms compete in prices under complete information about cost conditions and current demand conditions. Modeling second stage short run competition as a complete information game is a standard assumption in the literature on asymmetric information games since the seminal work of Milgrom and Roberts (1982). We will discuss the robustness of our results to the relaxation of this assumption in the next section.

We define $\pi_{i}\left(x_{1}, x_{2}, C_{1}\right), i=1,2$, as the profit of firm $i$ resulting from the short run competition in prices, when the pair of locations is $\left(x_{1}, x_{2}\right)$ and firm 1 bears cost $C_{1}$. Let $\mathcal{M}$ denote the set of all probability distributions defined on $\left\{\underline{C_{1}}, \overline{C_{1}}\right\}$ and $\hat{x}_{2}:[0, \ell / 2] \times \mathcal{M} \longrightarrow[\ell / 2, \ell]$ be firm 2's best response function so that $\hat{x}_{2}\left(x_{1}, \mu\right)$ is the location chosen by firm 2 with beliefs $\mu \in \mathcal{M}$ given location $x_{1}$ of firm 1 .

Calculations similar to those of Appendix A3 lead to:

$$
\frac{\partial \pi_{1}\left(x_{1}, x_{2}, C_{1}\right)}{\partial x_{1}}=\frac{\left(k\left(x_{2}-x_{1}\right)\left(2 \ell+x_{1}+x_{2}\right)-\Delta\right)\left(k\left(x_{2}-x_{1}\right)\left(x_{2}-3 x_{1}-2 \ell\right)-\Delta\right)}{18 k\left(x_{2}-x_{1}\right)^{2}}
$$


It is then straightforward to obtain the following "single-crossing" property

$$
\frac{\partial \pi_{1}\left(x_{1}, x_{2}, \overline{C_{1}}\right)}{\partial x_{1}}<\frac{\partial \pi_{1}\left(x_{1}, x_{2}, \underline{C_{1}}\right)}{\partial x_{1}} .
$$

Hence moving toward the market center is easier for the low cost firm 1 than for the high cost firm 1, or equivalently the cost of signaling one's type by locating closer to the market center is positively correlated with the firm's production cost. Under incomplete information, locations somewhat closer to the market center by firm 1 may be perceived as a signal of strength by firm 2. Consequently, such locations may be at the same time attractive for a low cost firm 1 willing to signal its real strength and for its high cost counterpart willing to appear as a low cost firm. The idea is that mimicking the low cost type induces firm 2 to differentiate more. However, firm 2 cannot choose a location beyond the market boundary. If the extent to which firm 2 differentiates its product is limited by the market boundary, mimicry is no longer attractive.

The analysis of location as a signal differs from the standard analysis in the literature on signaling games, even if the modeling strategy we use is rather standard in the literature on product differentiation. From Proposition 2, we know that under perfect information, firm 2 has a dominant strategy, namely to locate at the right end point of the market when its cost is higher than firm 1. Furthermore, Proposition 1 shows that, when it bears a lower cost than firm 1, firm 2 adopts the same equilibrium location although not the same equilibrium strategy. In particular, observing "puppy dog" locations near the opposite boundary induces firm 2 to behave also as a "puppy dog" by locating at the right end of the market while observing more aggressive locations closer to the market center induces firm 2 to respond aggressively at the market center. Thus whatever firm 2's beliefs regarding firm 1's cost, it will choose to locate at the right end point. ${ }^{5}$ It follows that the equilibrium locations under asymmetric information are exactly the same as under complete information. Let $x_{i}\left(C_{1}\right)$ denote the equilibrium location chosen by firm $i$ where $C_{1}$ is firm 1's true cost.

Proposition 3: The equilibria are independent of $\mu$ :

1. If $-5 \ell^{2} / 4<\underline{\Delta} / k<-\ell^{2}$ and $0<\bar{\Delta} / k<\ell^{2}$, we have a unique separating equilibrium:

$$
x_{1}\left(\overline{C_{1}}\right)=0, x_{1}\left(\underline{C_{1}}\right)=\left(\ell-\left(4 \ell^{2}+3 \underline{\Delta} / k\right)^{1 / 2}\right) / 3, x_{2}\left(\overline{C_{1}}\right)=x_{2}\left(\underline{C_{1}}\right)=\ell
$$

2. If $-\ell^{2} \leq \underline{\Delta} / k<0$ and $0<\bar{\Delta} / k \leq \ell^{2}$, we have a unique pooling equilibrium:

$$
x_{1}\left(\overline{C_{1}}\right)=x_{1}\left(\underline{C_{1}}\right)=0, x_{2}\left(\overline{C_{1}}\right)=x_{2}\left(\underline{C_{1}}\right)=\ell \|
$$


Proof: The equilibrium location $x_{1}^{N}$ under complete information maximizes on $[0, \ell / 2]$ the function $\pi_{1}\left(x_{1}, \ell, C_{1}\right)$ defined by $\hat{\pi}_{1}\left(x_{1}\right)$ for a given $C_{1}$ (see Appendices A3 and A5 for an explicit definition of $\hat{\pi}_{1}\left(x_{1}\right)$ for each value of $\left.C_{1}\right)$. The location $x_{2}^{N}\left(x_{1}\right)=\ell$ is firm 2's best response to any $x_{1}$ for any value of $\bar{\Delta} / k \in\left(0,3 \ell^{2} / 4\right)$ (see Proposition 1 ) and for any value of $\underline{\Delta} / k \in\left(-5 \ell^{2} / 4,0\right)$ (see Proposition 2). Thus, for any $x_{1}$ in $\left[0, \min \left\{\left(\ell^{2}-\Delta / k\right)^{1 / 2},\left(9 \ell^{2} / 4-\Delta / k\right)^{1 / 2}-\ell\right\}\right.$ ), and whatever $\mu \in[0,1]$, we have $\hat{x}_{2}\left(x_{1}, \mu\right)=\ell$. Firm 2's beliefs do not influence its behavior, although they affect its strategy: it locates at the right end point of the market. For all $\mu \in[0,1]$ and all $C_{1} \in\left\{\underline{C_{1}}, \overline{C_{1}}\right\}$, the location $x_{1}^{N}$ maximizes $\pi_{1}\left(x_{1}, \hat{x}_{2}\left(x_{1}, \mu\right), C_{1}\right)=\pi_{1}\left(x_{1}, \ell, C_{1}\right)$ on $[0, \ell / 2]$. Thus, were $x_{1}$ different from $x_{1}^{N}$, any type of firm 1 could deviate to $x_{1}^{N}$ and increase its profit. QED

Although the equilibrium locations are the same under complete and incomplete information, it is important to realize that this results from the fact that in the first case of Proposition 3 , firm 2 does react to the potential bluff by the high cost firm 1 when the latter deviates from its equilibrium location $x_{1}^{N}\left(\overline{C_{1}}\right)=0$. If the high cost firm 1 imitates the low cost firm 1 by locating at $x_{1}\left(\underline{C_{1}}\right)=\left(\ell-\left(4 \ell^{2}+3 \underline{\Delta} / k\right)^{1 / 2}\right) / 3$, then firm 2 , believing (wrongly) that it is facing a low cost firm 1 would change its strategy from $x_{2}^{+}(0)$ to $\ell$. Hence, although no change in equilibrium locations is observed, there is an important change in the strategy of firm 2 supporting the locations. However, one can check that the product differentiation obtained by mimicking, namely $\ell-x_{1}\left(\underline{C_{1}}\right)$, is lower than the equilibrium product differentiation given by $x_{1}^{+}(0)$. The reason is that firm 2 is limited in its possibility to differentiate by the market boundary.

Unlike what happens in standard models of signaling, the weaker type of sender, that is the high cost firm 1 in the present model, has no incentive to mimic its stronger counterpart because the signal received by firm 2 does not change its behavior. Even in the case $\underline{\Delta} / k \in\left(-5 \ell^{2} / 4,-\ell^{2}\right)$ where the low cost firm 1 does not locate at the left boundary of the market when it is perfectly identified, the high cost firm 1 is worse off if it deviates from 0 . If it was to locate slightly to the right of the left boundary in an attempt to trick its uninformed competitor, it would reduce product differentiation, would make price competition more severe and would end up with a reduction in profit.

This characteristic of the location model is noteworthy: when the natural boundaries of the market constrain a firm to locate at the end point regardless of its beliefs, strategic imitation is unprofitable. The low cost firm 1 is thereby not compelled to incur a distortion cost to separate 
itself, contrary to the usual case in the signaling literature. Therefore this low cost firm chooses the same location as under complete information.

The situation would change if firm 2 observing firm 1's location at the left end point had enough space to react differently depending upon firm 1's type. This would be the case for values of $\bar{\Delta} / k \in\left(\ell^{2}, 5 \ell^{2} / 4\right)$. Then, given $x_{1}$, firm 2's best reaction would be to locate at the boundary $\ell$ for sufficiently high values of $\mu$, but to the left of the end point for lower values of $\mu$, namely at $x_{2}^{+}\left(x_{1}\right)=\left(2\left(x_{1}+\ell\right)+\left(\left(x_{1}-2 \ell\right)^{2}-3 \bar{\Delta} / k\right)^{1 / 2}\right) / 3$ if firm 1 was perceived to be of the high cost type for sure $(\mu=0)$. Hence it could be profitable for the high cost firm 1 to be perceived as a low cost firm 1 in order to induce firm 2 to locate further away. One can then expect some distortions in locations or product characteristics to emerge with respect to the equilibria under complete information. The analysis would then be the same as in Boyer et al. $(1994,1995)$ modeling an industry where product differentiation is not constrained by the market boundaries.

\section{Robustness of the Results}

Two main features characterize the information structure of the present model: first, there is asymmetric information at the location stage where one of the firms has imperfect information about the rival's cost; second, there is perfect information at the price competition stage. We discussed above the rationale for such assumptions. Nevertheless one can wonder how the results would be affected were these assumptions relaxed.

Let us first consider what would happen at the location stage if each firm was uncertain about the other's cost. Clearly, if firm 1 ignores firm 2's cost, the latter will not distort its location choice strategy unless the sequence of moves is changed. Since firm 1 has already decided on its location at the time firm 2 locates, the latter's decision cannot influence the former's choice. Moreover, firm 2 has no incentive to distort its location to convey information since costs will be perfectly known at the price setting stage. Therefore firm 2's location strategy will remain the same and it will locate at the right end point whether its cost is perfectly known to firm 1 or not.

Firm 1, when imperfectly informed about firm 2's cost, may not choose the same location as in Proposition 3. In case 1 of Proposition 3, the equilibrium location of firm 1 when fully informed is shown to depend on whether its cost is higher or lower than firm 2's cost. Under 
symmetric cost uncertainty, the first mover firm 1 cannot do better than maximize its expected profit by choosing a location between $x_{1}\left(\overline{C_{1}}\right)$ and $x_{1}\left(\underline{C_{1}}\right)$ depending on its beliefs regarding firm 2 's cost. On the other hand, in case 2 of Proposition 3, firm 1 will not change its location which in equilibrium will remain at the left end point whatever its cost advantage or disadvantage. Thus in that case, not knowing firm 2's cost will not affect the location choice of firm 1.

Let us now consider our assumption of complete information at the pricing stage. Let us suppose that firm 2 does not know firm 1's cost at the price competition stage, which requires a pooling equilibrium at the location stage. As suggested by an anonymous referee, "... the low cost leader has incentive to pretend that it is a high cost firm ..." when choosing location to benefit from softer price competition with respect to the Bertrand equilibrium level under complete information. Indeed if the location stage fails to reveal firm 1's cost, we then face a simultaneous move price setting competition game where one firm is fully informed of market conditions while the other has imperfect information on its rival's cost. The imperfectly informed firm 2 will choose its price to maximize its expected profit given the observed locations chosen by the firms at stage one and given that firm 1 can be of one of two types. This price will be between the high price firm 2 would choose if firm 1 is known to be of the high cost type and the low price it would choose if firm 1 is known to be of the low cost type and its exact price level will depend on firm 2's beliefs as to the cost of the incumbent. Hence, provided that firm 2 fails to infer the true cost of firm 1 at the location stage, firm 2 will relax price competition when perceiving firm 1 to be more likely of the high cost type. Firm 1, knowing whether it has a cost advantage or not and anticipating the price chosen by firm 2 , will choose its best reply price which of course depends on whether it is a low cost firm or a high cost firm. If the price chosen by firm 1 reveals its type, then all subsequent price competition periods will be characterized by perfect information. Then, for all practical purposes, the price competition stage is a full information competition stage as in section 3 above. If on the other hand, the price chosen by firm 1 is independent of its type (pooling), then no information is revealed and the first period short run equilibrium is indefinitely repeated. If a pooling equilibrium exists at the pricing stage, meaning that information is conveyed neither through location nor through price, we obtain a price rigidity that may have similar consequences to the result of Bester (1998): relaxing price competition through spatial differentiation becomes less valuable, hence the equilibrium outcome may be characterized by less differentiation when firm 1 actually has a cost advantage. 


\section{Conclusion}

We have shown that information asymmetry may not cause any distortion in product differentiation. The result is obtained in the standard model of spatial competition under mill pricing and quadratic transportation costs. This contrasts with the main result of the literature on signaling which stresses that information asymmetry has a non negligible impact on strategic behavior. It complements also the results derived by Boyer et al. $(1994,1995)$ under discriminatory pricing and linear transportation costs where locations are indeed modified by the presence of signaling costs.

In the standard version of Hotelling's framework, a firm which observes its competitor's location before choosing its own location always responds by locating at the end point of the market. This tendency to move far apart (maximal differentiation) does not depend on the level of its production cost as long as both firms enjoy a positive market share and the market is totally covered. Thus, when a firm is uncertain of its competitor's efficiency, its perception or belief regarding the cost differential does not influence its strategic behavior: the firm sticks to the boundary of the market whatever its beliefs. The observation of the signal (location) sent by the privately informed firm keeps the uninformed firm's response unchanged. The informed firm in turn anticipates this when choosing its location, hence any distortion with respect to its full information behavior is unprofitable.

A noteworthy feature of our model is that a mimicking strategy to locate aggressively closer to the market center fails to increase the profit of the high cost firm. Even if it is believed to be a low cost firm by the uninformed firm, the latter cannot move further away than the market end point. The presence of a significant fixed cost of entry could change this result since the uninformed firm's decision to enter or not would then depend on its observation of the informed firm's location and on its inference regarding the cost differential. ${ }^{6}$ The result that firms locate as they would in a context of complete information could lead to the conclusion that information does not matter under spatial competition. We know from Boyer et al. $(1994,1995)$ that it is not true. 


\section{APPENDIX}

\section{A1. The Demand Functions}

Let $D_{i}\left(x_{1}, x_{2}, p_{1}, p_{2}\right)$ be the demand of firm $i$. It is straightforward to show that for any $x_{1} \neq x_{2}$, firms' demands are given, respectively, by

$$
\begin{gathered}
D_{1}\left(x_{1}, x_{2}, p_{1}, p_{2}\right)= \begin{cases}0, & \text { if } \frac{x_{1}+x_{2}}{2}+\frac{p_{2}-p_{1}}{2 k\left(x_{2}-x_{1}\right)}<0 \\
\frac{x_{1}+x_{2}}{2}+\frac{p_{2}-p_{1}}{2 k\left(x_{2}-x_{1}\right)}, & \text { if } 0 \leq \frac{x_{1}+x_{2}}{2}+\frac{p_{2}-p_{1}}{2 k\left(x_{2}-x_{1}\right)} \leq \ell \\
\ell, & \text { otherwise }\end{cases} \\
D_{2}\left(x_{1}, x_{2}, p_{1}, p_{2}\right)= \begin{cases}0, & \text { if } \frac{2 \ell-x_{1}-x_{2}}{2}+\frac{p_{1}-p_{2}}{2 k\left(x_{2}-x_{1}\right)}<0 \\
\frac{2 \ell-x_{1}-x_{2}}{2}+\frac{p_{1}-p_{2}}{2 k\left(x_{2}-x_{1}\right)}, & \text { if } 0 \leq \frac{2 \ell-x_{1}+x_{2}}{2}+\frac{p_{1}-p_{2}}{2 k\left(x_{2}-x_{1}\right)} \leq \ell \\
\ell, & \text { otherwise }\end{cases}
\end{gathered}
$$

It is easily seen that, for any location pair $\left(x_{1}, x_{2}\right)$, the profit functions are quasi-concave in prices, which ensures the existence of a corresponding price equilibrium and that this price equilibrium is unique. Furthermore, the first-order necessary conditions yield the expressions for those prices given in Lemma 1. By substituting them into the demand function of both firms, we get the expressions of the firms' reduced-form profit functions conditional on their locations.

\section{A2. The Monopolization of the Market by Firm 2 (Lemma 2)}

From the expressions of $D_{1}\left(x_{1}, x_{2}, p_{1}, p_{2}\right)$ given in A1 above, and of $p_{i}^{N}\left(x_{1}, x_{2}\right), i=1,2$, given in Lemma 1 , some calculations show that for any $x_{1} \neq x_{2}$ :

$$
D_{1}\left(x_{1}, x_{2}\right)=\frac{k\left(x_{2}-x_{1}\right)\left(2 \ell+x_{1}+x_{2}\right)-\Delta}{6 k\left(x_{2}-x_{1}\right)}=\frac{p_{1}^{N}\left(x_{1}, x_{2}\right)-C_{1}}{2 k\left(x_{2}-x_{1}\right)} .
$$

$\operatorname{Thus} \operatorname{sign}\left(D_{1}\left(x_{1}, x_{2}\right)\right)=\operatorname{sign}\left(p_{1}^{N}\left(x_{1}, x_{2}\right)-C_{1}\right)=\operatorname{sign}\left(x_{2}^{2}+2 \ell x_{2}-x_{1}\left(2 \ell+x_{1}\right)-\Delta / k\right)$. The latter function is parabolic in $x_{2}$. Let $x_{2}^{+}$be the largest root of the equation $x_{2}^{2}+2 \ell x_{2}-$ $x_{1}\left(2 \ell+x_{1}\right)-\Delta / k=0$. Then:

$$
x_{2}^{+}=-\ell+\sqrt{\delta_{1}} \text { where } \delta_{1}=\left(x_{1}+\ell\right)^{2}+\Delta / k \text {. }
$$


Hence, given $x_{1}$, if $x_{2}^{+}$is higher than $\ell / 2$, then for any $x_{2} \leq x_{2}^{+}, D_{1}\left(x_{1}, x_{2}\right)=0$ and firm 1 's profit is zero. The inequality $\ell / 2 \leq x_{2}^{+}$is equivalent to:

$$
x_{1}^{2}+2 \ell x_{1}+\Delta / k-5 \ell^{2} / 4 \geq 0
$$

Let $x_{1}^{+}$denote the largest root of the above equation. We have:

$$
x_{1}^{+}=-\ell+\sqrt{\delta_{2}} / 2 \text { where } \delta_{2}=9 \ell^{2} / 4-\Delta / k .
$$

Thus, if $x_{1}^{+} \leq 0$, then for any $x_{1} \geq 0$ we have $\ell / 2 \leq x_{2}^{+}$and there exists some location $x_{2} \in[\ell / 2, \ell]$ for which firm 1's profit is zero. But $x_{1}^{+} \leq 0$ if and only if $\Delta / k \geq 5 \ell^{2} / 4$.

\section{A3. Firm 1's Reduced-form Profit Function $\hat{\pi}\left(x_{1}\right)$ for $\Delta>0$}

From Lemma 2, we know that if $x_{1} \in\left[\left(9 \ell^{2} / 4-\Delta / k\right)^{1 / 2}-\ell, \ell / 2\right]$, then firm 2 captures the whole market, thus is better off locating at $\ell / 2$. Let $\bar{x}_{1}$ denote $\left(9 \ell^{2} / 4-\Delta / k\right)^{1 / 2}-\ell$. We shall take $x_{1}$ to be lower than $\bar{x}_{1}$, hence $D_{1}\left(x_{1}, x_{2}\right)>0$ for all $x_{2}$ (see Figure 1 ).

[Insert Figure 1 here]

We first compute firm 2's best response given firm 1's location. Let $\pi_{i}\left(x_{1}, x_{2}\right)$ denote firm $i$ 's reduced-form profit function. From the envelope theorem, we have:

$$
\frac{\partial \pi_{2}\left(x_{1}, x_{2}\right)}{\partial x_{2}}=\left(p_{2}^{N}\left(x_{1}, x_{2}\right)-C_{2}\right)\left(\frac{\partial D_{2}(\cdot)}{\partial x_{2}}+\frac{\partial D_{2}(\cdot)}{\partial p_{1}} \frac{d p_{1}^{N}(\cdot)}{d x_{2}}\right) .
$$

From the expressions in A1 and Lemma 1, it follows that:

$$
\frac{\partial D_{2}(\cdot)}{\partial x_{2}}=\frac{5 x_{2}-x_{1}-2 \ell}{6\left(x_{1}-x_{2}\right)}-\frac{\Delta}{6 k\left(x_{2}-x_{1}\right)^{2}} ; \frac{\partial D_{2}(\cdot)}{\partial p_{1}}=\frac{1}{2 k\left(x_{2}-x_{1}\right)} ; \frac{d p_{1}^{N}(\cdot)}{d x_{2}}=\frac{2 k\left(\ell+x_{2}\right)}{3} .
$$

Hence:

$$
\frac{\partial \pi_{2}\left(x_{1}, x_{2}\right)}{\partial x_{2}}=\frac{\left(k\left(x_{2}-x_{1}\right)\left(4 \ell-x_{2}-x_{1}\right)+\Delta\right)\left(k\left(x_{2}-x_{1}\right)\left(4 \ell+x_{1}-3 x_{2}\right)-\Delta\right)}{18 k\left(x_{2}-x_{1}\right)}
$$

By assumption $x_{2}>x_{1}$. Moreover if firm 2's demand is positive then $k\left(x_{2}-x_{1}\right)\left(4 \ell-x_{2}-x_{1}\right)+\Delta>0$ as can be shown by the following expression:

$$
D_{2}\left(x_{1}, x_{2}\right)=\frac{\left(k\left(x_{2}-x_{1}\right)\left(4 \ell-x_{2}-x_{1}\right)+\Delta\right)}{6 k\left(x_{2}-x_{1}\right)}=\frac{p_{2}^{N}\left(x_{1}, x_{2}\right)-C_{2}}{2 k\left(x_{2}-x_{1}\right)} .
$$


Thus, given $x_{1}$, we must calculate for which value of $x_{2} \in[\ell / 2, \ell]$, the expression $k\left(x_{2}-x_{1}\right)\left(4 \ell+x_{1}-3 x_{2}\right)-\Delta$ is equal to 0 , in order to study the first-order conditions for maximizing $\pi_{2}\left(x_{1}, x_{2}\right)$. Let us solve the equivalent equation in $x_{2}$ :

$$
-3 x_{2}^{2}+4\left(x_{1}+\ell\right) x_{2}-x_{1}\left(4 \ell+x_{1}\right)-\Delta / k=0 .
$$

Let $\delta_{3}\left(x_{1}\right) \equiv\left(x_{1}-2 \ell\right)^{2}-3 \Delta / k$. Straightforward calculations lead to the following:

- if $\Delta / k<3 \ell^{2} / 4$, then, for any $x_{1} \in[0, \ell / 2], \delta_{3}\left(x_{1}\right)>0$;

- if $3 \ell^{2} / 4 \leq \Delta / k \leq 4 \ell^{2} / 3$, then, for any $x_{1} \in\left[0,2 \ell-(3 \Delta / k)^{\frac{1}{2}}\right], \delta_{3}\left(x_{1}\right) \geq 0$

and for any $x_{1} \in\left(2 \ell-(3 \Delta / k)^{\frac{1}{2}}, \ell / 2\right], \delta_{3}\left(x_{1}\right)<0$;

- if $4 \ell^{2} / 3<\Delta / k$, then, for any $x_{1} \in[0, \ell / 2], \delta_{3}\left(x_{1}\right)<0$.

Figure 2 shows that the constraint $x_{1}<\bar{x}_{1}$ implies that $x_{1}<2 \ell-(3 \Delta / k)^{\frac{1}{2}}$, hence $\delta_{3}\left(x_{1}\right)>0$. Consequently, the roots $x_{2}^{-}\left(x_{1}\right)$ and $x_{2}^{+}\left(x_{1}\right)$ are well defined and given by:

$$
x_{2}^{-}\left(x_{1}\right)=\left(2\left(x_{1}+\ell\right)-\sqrt{\delta_{3}\left(x_{1}\right)}\right) / 3 \text { and } x_{2}^{+}\left(x_{1}\right)=\left(2\left(x_{1}+\ell\right)+\sqrt{\delta_{3}\left(x_{1}\right)}\right) / 3 .
$$

Further calculations lead to the following inequalities:

$$
\text { For any } x_{1} \in\left[0, \bar{x}_{1}\right): 0<x_{2}^{-}\left(x_{1}\right)<\ell / 2<x_{2}^{+}\left(x_{1}\right) \text {. }
$$

Indeed, $0<x_{2}^{-}\left(x_{1}\right)$ can be rewritten $0<3 x_{1}^{2}+4 \ell x_{1}+3 \Delta / k$, which is met, and $\ell / 2<x_{2}^{+}\left(x_{1}\right)$ can be rewritten $4 x_{1}+\ell+2 \sqrt{\delta_{3}\left(x_{1}\right)}>0$, which is also verified. Finally, $x_{2}^{-}\left(x_{1}\right)<\ell / 2$ is equivalent to $x_{1}^{2}+2 \ell x_{1}-5 \ell^{2} / 4+\Delta / k<0$ : letting $\varphi\left(x_{1}\right)$ denote $x_{1}^{2}+2 \ell x_{1}-5 \ell^{2} / 4+\Delta / k$, it is useful to remark that $x_{1}=\bar{x}_{1}$ is the upper root of $\varphi\left(x_{1}\right)=0$, thus for all $x_{1}<\bar{x}_{1}$ we have $\varphi\left(x_{1}\right)<0$. A straightforward consequence of $x_{2}^{-}\left(x_{1}\right)<\ell / 2$ is that the profit function $\pi_{2}\left(x_{1}, x_{2}\right)$ admits only one maximum inside $[\ell / 2, \ell]$, given either by $\ell$ or by $x_{2}^{+}\left(x_{1}\right)$. Moreover, it can be checked that $x_{2}^{+}\left(x_{1}\right) \leq \ell$ is met for any $x_{1} \geq\left(\ell^{2}-\Delta / k\right)^{\frac{1}{2}}$.

Figure 2 summarizes those results. Three regions are of interest. In region 1 where $x_{1}>$ $\bar{x}_{1}, D_{1}\left(x_{1}, x_{2}\right)<0$ for all $x_{2}$, thus firm 2's best response is to locate at $\ell / 2$. In region 2 where $x_{1}<\min \left(\bar{x}_{1},\left(\ell^{2}-\Delta / k\right)^{\frac{1}{2}}\right)$, first $D_{1}\left(x_{1}, x_{2}\right)>0$ for all $x_{2}$ and second $x_{2}^{+}\left(x_{1}\right)>\ell$, thus firm 2 's best response is to locate at $\ell$. In region 3 where $\left(\ell^{2}-\Delta / k\right)^{\frac{1}{2}}<x_{1}<\bar{x}_{1}$, first $D_{1}\left(x_{1}, x_{2}\right)>0$ for all $x_{2}$ and second $x_{2}^{+}\left(x_{1}\right)<\ell$, thus firm 2's best response is to locate at $x_{2}^{+}\left(x_{1}\right)$. Firm 2's best responses are depicted in Figure 3 for the different values of $\Delta / k$. 
[Insert Figure 2 here]

[Insert Figure 3 here]

We can now substitute firm 2's best response expressions into firm 1's reduced-form profit function and get the function $\hat{\pi}_{1}\left(x_{1}\right)$, decreasing in $x_{1}$ :

1. If $0 \leq \Delta / k \leq 3 \ell^{2} / 4$

$$
\hat{\pi}_{1}\left(x_{1}\right)=\left\{\begin{array}{l}
\left(k\left(\ell-x_{1}\right)\left(3 \ell+x_{1}\right)-\Delta\right)^{2} / 18 k\left(\ell-x_{1}\right), \\
0, \text { otherwise }
\end{array}\right.
$$

2. If $3 \ell^{2} / 4<\Delta / k<\ell^{2}$

$$
\hat{\pi}_{1}\left(x_{1}\right)=\left\{\begin{array}{c}
\left(k\left(\ell-x_{1}\right)\left(3 \ell+x_{1}\right)-\Delta\right)^{2} / 18 k\left(\ell-x_{1}\right), \\
\quad \text { if } x_{1} \in\left[0,\left(\ell^{2}-\Delta / k\right)^{1 / 2}\right] \\
\left(k\left(x_{2}^{+}\left(x_{1}\right)-x_{1}\right)\left(2 \ell+x_{2}^{+}\left(x_{1}\right)+x_{1}\right)-\Delta\right)^{2} / 18 k\left(x_{2}^{+}\left(x_{1}\right)-x_{1}\right), \\
\quad \text { if } x_{1} \in\left[\left(\ell^{2}-\Delta / k\right)^{1 / 2},\left(9 \ell^{2} / 4-\Delta / k\right)^{1 / 2}-\ell\right] \\
\begin{array}{l}
0, \text { otherwise }
\end{array}
\end{array}\right.
$$

Using the envelope theorem, we obtain:

$$
\begin{aligned}
\frac{\partial \pi_{1}\left(x_{1}, x_{2}\right)}{\partial x_{2}} & =\left(p_{1}^{N}\left(x_{1}, x_{2}\right)-C_{1}\right)\left(\frac{\partial D_{1}(\cdot)}{\partial x_{2}}+\frac{\partial D_{1}(\cdot)}{\partial p_{2}} \frac{d p_{2}^{N}(\cdot)}{d x_{2}}\right) \\
& =\frac{\left(p_{1}^{N}\left(x_{1}, x_{2}\right)-C_{1}\right)\left(k\left(x_{2}-x_{1}\right)\left(2 \ell+3 x_{2}-x_{1}\right)+\Delta\right)}{6 k\left(x_{2}-x_{1}\right)^{2}} .
\end{aligned}
$$

Hence, given any $\left(x_{1}, x_{2}\right) \in[0, \ell / 2] \times[\ell / 2, \ell]$, if $\Delta>0$ then:

$$
\frac{\partial \pi_{1}\left(x_{1}, x_{2}\right)}{\partial x_{2}}>0
$$

Thus the function $\hat{\pi}_{1}\left(x_{1}\right)$ is continuously decreasing for $x_{1} \in\left[0,\left(9 \ell^{2} / 4-\Delta / k\right)^{1 / 2}-\ell\right]$ and non-differentiable at $x_{1}=\left(\ell^{2}-\Delta / k\right)^{1 / 2}$.

3. If $\ell^{2} \leq \Delta / k<5 \ell^{2} / 4$

$$
\hat{\pi}_{1}\left(x_{1}\right)=\left\{\begin{array}{cc}
\left(k\left(x_{2}^{+}\left(x_{1}\right)-x_{1}\right)\left(2 \ell+x_{2}^{+}\left(x_{1}\right)+x_{1}\right)-\Delta\right)^{2} / 18 k\left(x_{2}^{+}\left(x_{1}\right)-x_{1}\right), \\
0, \text { otherwise } & \text { if } x_{1} \in\left[0,-\ell+\left(9 \ell^{2} / 4-\Delta / k\right)^{1 / 2}\right)
\end{array}\right.
$$




\section{A4. Proof of Lemma 3}

We know from A3 above that

$$
D_{2}\left(x_{1}, x_{2}\right)=\frac{p_{2}^{N}\left(x_{1}, x_{2}\right)-C_{2}}{2 k\left(x_{2}-x_{1}\right)}=\frac{k\left(x_{2}-x_{1}\right)\left(4 \ell-x_{2}-x_{1}\right)+\Delta}{6 k\left(x_{2}-x_{1}\right)}
$$

Since $x_{2}>x_{1}$, then $D_{2}\left(x_{1}, x_{2}\right)>0$ is equivalent to the following inequality:

$$
x_{1}^{2}-4 \ell x_{1}+4 \ell x_{2}-x_{2}^{2}+\Delta / k>0 .
$$

Let $\delta_{4}$ and $x_{1}^{-}$denote respectively the discriminant and the lower root of equation $x_{1}^{2}-4 \ell x_{1}+$ $4 \ell x_{2}-x_{2}^{2}+\Delta / k=0$. Their expression is given by:

$$
\delta_{4}=\left(2 \ell-x_{2}\right)^{2}-\Delta / k \text { and } x_{1}^{-}=-\ell+\sqrt{\delta_{4}} .
$$

The higher root is obviously always higher than $\ell / 2$ for any $x_{1} \in[0, \ell / 2]$, hence doesn't matter. Thus, if $x_{1}^{-} \in[0, \ell / 2]$, then for any $x_{1} \geq x_{1}^{-}$, we have $D_{2}\left(x_{1}, x_{2}\right)=0$ and if $x_{1}^{-}>\ell / 2$, then for any $x_{1} \in[0, \ell / 2]$, we have $D_{2}\left(x_{1}, x_{2}\right)>0$.

The inequality $x_{1}^{-}>\ell / 2$ can be rewritten as follows:

$$
x_{2}^{2}-4 \ell x_{2}+7 \ell^{2} / 4-\Delta / k<0 \text {. }
$$

Let $x_{2}^{-}$denote the smallest root of equation $x_{2}^{2}-4 \ell x_{2}+7 \ell^{2} / 4-\Delta / k=0$. If $x_{2}^{-}<\ell$, then for any $x_{2}>x_{2}^{-}$, we have $x_{1}^{-}>\ell / 2$. One can show that $x_{2}^{-}=2 \ell-\left(9 \ell^{2} / 4+\Delta / k\right)^{1 / 2}<\ell$ if and only if $-5 \ell^{2} / 4<\Delta / k$.

\section{A5. Firms 1's Reduced-form Profit Function for $\Delta<0$}

By using the envelope theorem, we can write:

$$
\frac{\partial \hat{\pi}_{1}\left(x_{1}\right)}{\partial x_{1}}=\frac{\partial \pi_{1}\left(x_{1}, \ell\right)}{\partial x_{1}}=\left(p_{1}^{N}\left(x_{1}, \ell\right)-C_{1}\right)\left(\frac{\partial D_{1}\left(x_{1}, \ell\right)}{\partial x_{1}}+\frac{\partial D_{1}\left(x_{1}, \ell\right)}{\partial p_{2}} \cdot \frac{d p_{2}^{N}\left(x_{1}, \ell\right)}{d x_{1}}\right)
$$

where from A1 above and Lemma 1,

$$
\begin{gathered}
D_{1}\left(x_{1}, \ell\right)=\frac{p_{2}^{N}-p_{1}^{N}}{2 k\left(\ell-x_{1}\right)}+\frac{x_{1}+\ell}{2} \\
\frac{\partial D_{1}(\cdot)}{\partial x_{1}}=\frac{3 \ell-5 x_{1}}{6\left(\ell-x_{1}\right)}-\frac{\Delta}{6 k\left(\ell-x_{1}\right)^{2}} \text { and } \frac{\partial D_{1}(\cdot)}{\partial p_{2}}=\frac{1}{2 k\left(\ell-x_{1}\right)}
\end{gathered}
$$




$$
\frac{d p_{2}^{N}(\cdot)}{d x_{1}}=\frac{2 k\left(x_{1}-2 \ell\right)}{3}
$$

Hence:

$$
\frac{\partial \hat{\pi}_{1}\left(x_{1}\right)}{\partial x_{1}}=\left(p_{1}^{N}\left(x_{1}, \ell\right)-C_{1}\right) \frac{\left(k\left(x_{1}-\ell\right)\left(\ell+3 x_{1}\right)-\Delta\right)}{6 k\left(\ell-x_{1}\right)^{2}}
$$

We thus have $\operatorname{sign} \partial \hat{\pi}_{1} / \partial x_{1}=\operatorname{sign}\left(k\left(x_{1}-\ell\right)\left(\ell+3 x_{1}\right)-\Delta\right)$. The study of equation $k\left(x_{1}-\ell\right)\left(\ell+3 x_{1}\right)-$ $\Delta=0$ in $x_{1}$, which admits $k\left(4 k \ell^{2}+3 \Delta\right)$ as a discriminant, shows that there does not exist any real root for $\Delta / k<-4 \ell^{2} / 3$ and there exists at least one root otherwise, more precisely two when $-4 \ell^{2} / 3<\Delta / k$. Both of them are critical points for the function $\hat{\pi}_{1}\left(x_{1}\right)$ defined on $\mathbb{R}$. Moreover the lower root is a local maximizer and the upper root is a local minimizer for any value of $\Delta / k>-4 \ell^{2} / 3$ since the inflexion point is a global minimizer of $\partial \hat{\pi}_{1} / \partial x_{1}$.

Let us compute $\partial \hat{\pi}_{1} / \partial x_{1}$ respectively at 0 and $\ell / 2$ :

$$
\begin{gathered}
\frac{\partial \hat{\pi}_{1}(0)}{\partial x_{1}}=\left(p_{1}^{N}(0, \ell)-C 1\right)\left(-\frac{\Delta+k \ell^{2}}{6 k \ell^{2}}\right) \leq 0 \text { iff } \Delta / k \frac{\geq}{<}-\ell^{2} \\
\frac{\partial \hat{\pi}_{1}(\ell / 2)}{\partial x_{1}}=\left(p_{1}^{N}(\ell / 2, \ell)-C 1\right)\left(-\frac{4 \Delta+5 k \ell^{2}}{6 k \ell^{2}}\right) \leq 0 \text { iff } \Delta / k \frac{\geq}{<}-5 \ell^{2} / 4,
\end{gathered}
$$

from which we conclude: if $\Delta / k \in\left(-4 \ell^{2} / 3,-5 \ell^{2} / 4\right]$, then both the local maximizer and minimizer of $\hat{\pi}_{1}\left(x_{1}\right)$ belongs to $[0, \ell / 2]$; if $\Delta / k \in\left(-5 \ell^{2} / 4,-\ell^{2}\right)$, then $\hat{\pi}_{1}\left(x_{1}\right)$ admits only the local maximizer in $[0, \ell / 2]$ and the local minimizer is higher than $\ell / 2$; finally if $\Delta / k \in\left(-\ell^{2}, 0\right)$, then $\hat{\pi}_{1}\left(x_{1}\right)$ is strictly decreasing on $[0, \ell / 2]$ since the local maximizer is lower than 0 and the local minimizer is higher than $\ell / 2$.

Thus a sufficient condition for $\hat{\pi}_{1}\left(x_{1}\right)$ to admit one and only one maximizer in $[0, \ell / 2]$ is to consider values of $\Delta / k$ in the interval $\left(-5 \ell^{2} / 4,0\right)$. We can define $\hat{\pi}_{1}\left(x_{1}\right)$ explicitly: if $-5 \ell^{2} / 4<$ $\Delta / k$, then, for any $x_{1} \in[0, \ell / 2]$

$$
\hat{\pi}_{1}\left(x_{1}\right)=\frac{\left(k\left(\ell-x_{1}\right)\left(3 \ell+x_{1}\right)-\Delta\right)^{2}}{18 k\left(\ell-x_{1}\right)} .
$$

The maximizer denoted $x_{1}^{N}$ in the text, is different or equal to 0 depending upon the level of $\Delta / k$, namely:

$$
x_{1}^{N}= \begin{cases}\left(\ell-\left(4 \ell^{2}+3 \Delta / k\right)^{1 / 2}\right) / 3>0, & \text { if } \Delta / k \in\left(-5 \ell^{2} / 4,-\ell^{2}\right] \\ 0, & \text { if } \Delta / k \in\left[-\ell^{2}, 0\right]\end{cases}
$$


since for any value of $\Delta / k \in\left(-5 \ell^{2} / 4,-\ell^{2}\right]$ :

$$
\partial \hat{\pi}_{1}\left(x_{1}\right) / \partial x_{1} \geq 0 \text { iff } x_{1} \frac{\leq}{>}\left(\ell-\left(4 \ell^{2}+3 \Delta / k\right)^{1 / 2}\right) / 3,
$$

and for any value of $\Delta / k \in\left[-\ell^{2}, 0\right]$ :

$$
\partial \hat{\pi}_{1}\left(x_{1}\right) / \partial x_{1} \leq 0 \text { whatever } x_{1} \in[0, \ell / 2] .
$$




\section{FOOTNOTES}

1. It could be argued that real transportation costs tend to be concave rather than convex; this may be the case in geographic space but clearly not a convincing argument in preference space.

2. Boyer et al. (1994, 1995) used refinements, such as the intuitive criterion and the D1 divinity criterion, to obtain a unique separating equilibrium, namely the one which involves the smallest distortion cost for the efficient incumbent, and a unique pooling equilibrium. Boyer et al. (2001) consider entry prevention in a location model of incomplete information with fixed and sunk entry costs.

3. See Appendix A5 for an explicit definition of $\hat{\pi}_{1}\left(x_{1}\right)$ in this case.

4. This situation is captured by a standard signaling game in locations; see Boyer et al. (1994, 1995).

5. In the language of signaling games, the assumption of stochastic dominance is not satisfied (see Cho and Sobel, 1990, assumption A3 page 391; or Mailath et alii, 1993, assumption 2 page $255)$, that is, for any $\mu \in[0,1]$ and given $x_{1}$ such that firm 1's profit is positive, $\hat{x}_{2}\left(x_{1}, \mu\right)=\ell$. For values of $\bar{\Delta} / k \in\left(\ell^{2}, 5 \ell^{2} / 4\right), \hat{x}_{2}\left(x_{1}, \mu\right)$ could be strictly lower than $\ell$ for some $\mu$ and some $x_{1}$ and the analysis would then be the same as in Boyer et al. $(1994,1995)$.

6. The problem of entry deterrence under incomplete information in a spatial context is studied in Boyer et al. (2001). 


\section{REFERENCES}

Financial support from SSHRC (Canada), INRA (France) and CNRS (France) is gratefully acknowledged.

BESTER, H., 1998, Quality Uncertainty Mitigates Product Differentiation, Rand Journal of Economics 29, 828-8444.

BOYER, M., J.J. LAFFONT, P. MAHENC and M. MOREAUX, 1994, Location Distortions under Asymmetric Information, Regional Science and Urban Economics 24, 409-440.

BOYER, M., J.J. LAFFONT, P. MAHENC and M. MOREAUX, 1995, Sequential Location Equilibria under Incomplete Information, Economic Theory 6, 323-350.

BOYER, M., P. MAHENC and M. MOREAUX, 2001, Entry Preventing Locations under Incomplete Information, mimeo, Université de Montréal and Université de Toulouse.

CHO, I.-K. and J. SOBEL, 1990, Strategic Stability and Uniqueness in Signaling Games, Journal of Economic Theory 20, 240-359.

D'ASPREMONT, C., J.J. GABSZEWICZ and J.F. THISSE, 1979, On Hotelling Stability in Competition, Econometrica 47, 1145-1150.

HOTELLING, H., 1929, Stability in Competition, Economic Journal 39, 41-57.

HURTER, A.P. and P.J. LEDERER, 1985, Spatial Duopoly with Discriminatory Pricing, Regional Science and Urban Economics 15, 541-553.

LEDERER, P.J. and A.P. HURTER, 1986, Competition of Firms : Discriminatory Pricing and Location, Econometrica 54, 623-640.

MAILATH, G., M. OKUNO-FUJIWARA and A. POSTLEWAITE, 1993, Belief-Based Refinements in Signaling Games, Journal of Economic Theory 60, 241-276. 
FIGURE 1

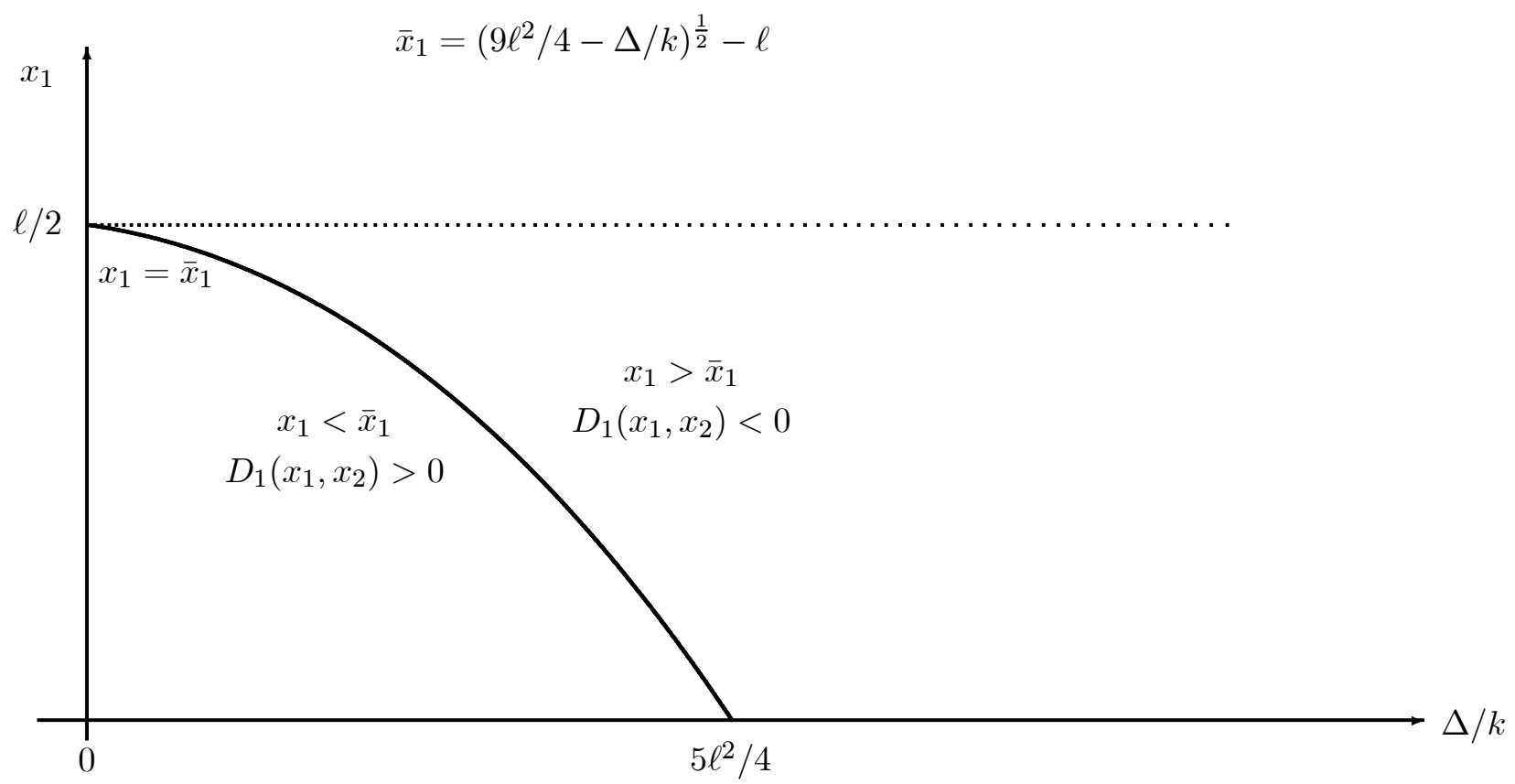


FIGURE 2

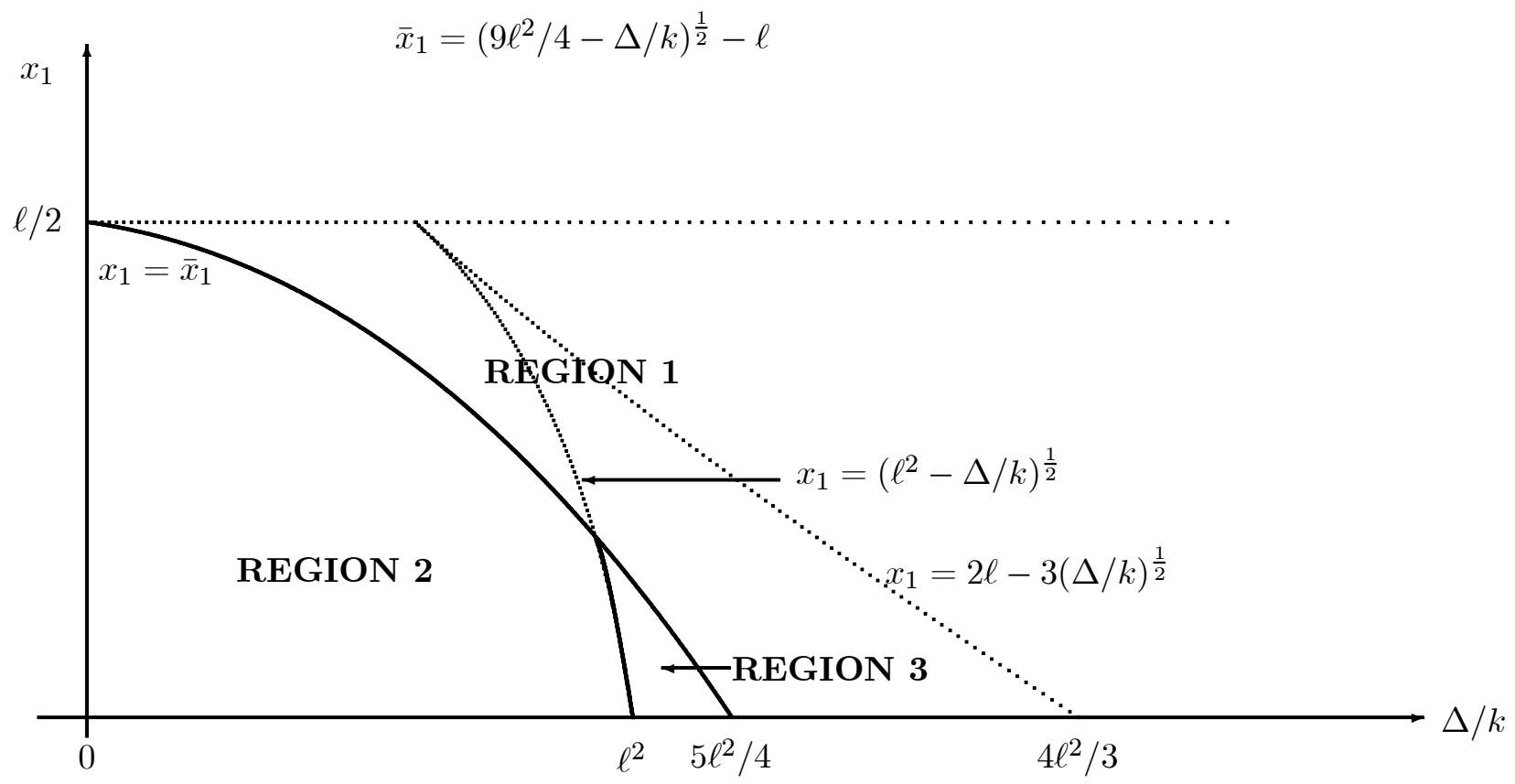


FIGURE 3

Firm 2's best response functions

$$
\begin{gathered}
\mathrm{A}=\left(9 \ell^{2} / 4-\Delta / k\right)^{\frac{1}{2}}-\ell \\
\mathrm{B}=\left(\ell^{2}-\Delta / k\right)^{\frac{1}{2}}
\end{gathered}
$$
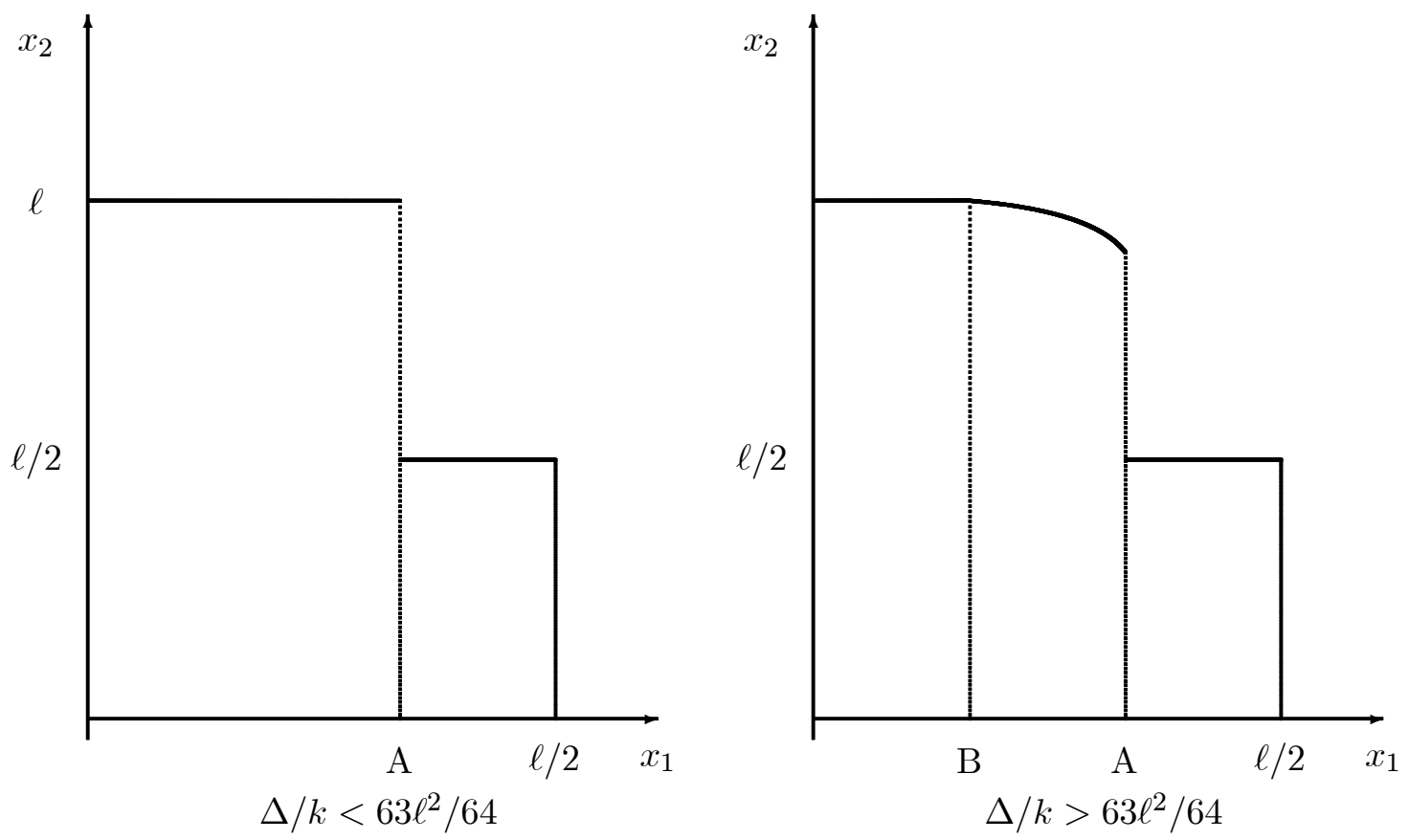


\section{Liste des publications au CIRANO*}

Série Scientifique / Scientific Series (ISSN 1198-8177)

2002s-16 Asymmetric Information and Product Differentiation / Marcel Boyer, Philippe Mahenc et Michel Moreaux

2002s-15 Entry Preventing Locations Under Incomplete Information / Marcel Boyer, Philippe Mahenc et Michel Moreaux

2002s-14 On the Relationship Between Financial Status and Investment in Technological Flexibility / Marcel Boyer, Armel Jacques et Michel Moreaux

2002s-13 Modeling the Choice Between Regulation and Liability in Terms of Social Welfare / Marcel Boyer et Donatella Porrini

2002s-12 Observation, Flexibilité et Structures Technologiques des Industries / Marcel Boyer, Armel Jacques et Michel Moreaux

2002s-11 Idiosyncratic Consumption Risk and the Cross-Section of Asset Returns / Kris Jacobs et Kevin Q. Wang

2002s-10 The Demand for the Arts / Louis Lévy-Garboua et Claude Montmarquette

2002s-09 Relative Wealth, Status Seeking, and Catching Up / Ngo Van Long, Koji Shimomura

2002s-08 The Rate of Risk Aversion May Be Lower Than You Think / Kris Jacobs

2002s-07 A Structural Analysis of the Correlated Random Coefficient Wage Regression Model / Christian Belzil et Jörgen Hansen

2002s-06 Information Asymmetry, Insurance, and the Decision to Hospitalize / Åke Blomqvist et Pierre Thomas Léger

2002s-05 Coping with Stressful Decisions: Individual Differences, Appraisals and Choice / Ann-Renée Blais

2002s-04 A New Proof Of The Maximum Principle / Ngo Van Long et Koji Shimomura

2002s-03 Macro Surprises And Short-Term Behaviour In Bond Futures / Eugene Durenard et David Veredas

2002s-02 Financial Asset Returns, Market Timing, and Volatility Dynamics / Peter F. Christoffersen et Francis X. Diebold

2002s-01 An Empirical Analysis of Water Supply Contracts / Serge Garcia et Alban Thomas

2001s-71 A Theoretical Comparison Between Integrated and Realized Volatilities Modeling / Nour Meddahi

2001s-70 An Eigenfunction Approach for Volatility Modeling / Nour Meddahi

2001s-69 Dynamic Prevention in Short Term Insurance Contracts / M. Martin Boyer et Karine Gobert

2001s-68 Serial Cost Sharing in Multidimensional Contexts / Cyril Téjédo et Michel Truchon

2001s-67 Learning from Strike / Fabienne Tournadre et Marie-Claire Villeval

* Consultez la liste complète des publications du CIRANO et les publications elles-mêmes sur notre site Internet : 
2001s-66 Incentives in Common Agency / Bernard Sinclair-Desgagné

2001s-65 Detecting Mutiple Breaks in Financial Market Volatility Dynamics / Elena Andreou et Eric Ghysels

2001s-64 Real Options, Preemption, and the Dynamics of Industry Investments / Marcel Boyer, Pierre Lasserre, Thomas Mariotti et Michel Moreaux

2001s-63 Dropout, School Performance and Working while in School: An Econometric Model with Heterogeneous Groups / Marcel Dagenais, Claude Montmarquette et Nathalie Viennot-Briot

2001s-62 Derivatives Do Affect Mutual Funds Returns : How and When? / Charles Cao, Eric Ghysels et Frank Hatheway

2001s-61 Conditional Quantiles of Volatility in Equity Index and Foreign Exchange Data / John W. Galbraith, Serguei Zernov and Victoria Zinde-Walsh

2001s-60 The Public-Private Sector Risk-Sharing in the French Insurance "Cat. Nat. System" / Nathalie de Marcellis-Warin et Erwann Michel-Kerjan

2001s-59 Compensation and Auditing with Correlated Information / M. Martin Boyer et Patrick González

2001s-58 Resistance is Futile: An Essay in Crime and Commitment / M. Martin Boyer

2001s-57 The Unreliability of Output Gap Estimates in Real Time / Athanasios Orphanides et Simon van Norden

2001s-56 Exact Nonparametric Two-Sample Homogeneity Tests for Possibly Discrete Distributions / Jean-Marie Dufour et Abdeljelil Farhat

2001s-55 Les coûts de la réglementation : une revue de la littérature / Robert Gagné, Paul Lanoie, Pierre-Carl Micheud et Michel Patry

2001s-54 Testing for structural Change in the Presence of Auxiliary Models / Eric Ghysels et Alain Guay

2001s-53 Environmental Regulation and Productivity: New Findings on the Porter Hypothesis / Paul Lanoie, Michel Patry et Richard Lajeunesse

2001s-52 The Aftermarket Performance of Initial Public Offerings in Canada / Maher Kooli et Jean-Marc Suret

2001s-51 Capital Structure and Risk Management / Karine Gobert

2001s-50 The Underpricing of Initial Public Offerings: Futher Canadian Evidence / Maher Kooli et Jean-Marc Suret

2001s-49 How Innovative Are Canadian Firms Compared to Some European Firms? A Comparative Look at Innovation Surveys / Pierre Mohnen et Pierre Therrien

2001s-48 A Tale of Two Ports / Ngo Van Long et Kar-yiu Wong

2001s-47 Wage Policy of Firms: An Empirical Investigation / Stéphanie Lluis

2001s-46 Forecasting Some Low-Predictability Time Series Using Diffusion Indices / Marc Brisson, Bryan Campbell et John W. Galbraith

2001s-45 The Importance of the Loss Function in Option Pricing / Peter Christoffersen et Kris Jacobs

2001s-44 Let's Get "Real" about Using Economic Data / Peter Christoffersen, Eric Ghysels et Norman R. Swanson

2001s-43 Fragmentation, Outsourcing and the Service Sector / Ngo Van Long, Ray 
Riezman et Antoine Soubeyran

2001s-42 Nonlinear Features of Realized FX Volatility / John M. Maheu et Thomas H.

McCurdy

2001s-41 Job Satisfaction and Quits: Theory and Evidence from the German

Socioeconomic Panel / Louis Lévy-Garboua, Claude Montmarquette et Véronique Simonnet

2001s-40 Logique et tests d'hypothèse : réflexions sur les problèmes mal posés en économétrie / Jean-Marie Dufour

2001s-39 Managing IT Outsourcing Risk: Lessons Learned / Benoit A. Aubert, Suzanne Rivard et Michel Patry

2001s-38 Organizational Design of R\&D Activities / Stefan Ambec et Michel Poitevin 